\title{
Improved Automatic Generation Control of Interconnected Power System
}

\author{
V.Jahnavi Reddy, K.Krushna Murthy, P.V. Bala Subramanyam
}

\begin{abstract}
In present day manage frameworks situation, the most intense significance is given to interconnection of different frameworks on the way to meet the dynamical modifications in burdens additionally energy movements via specific elements. it's miles essential to manipulate the framework recurrence and tie-line streams of an interconnected electricity framework. Albeit, normal controllers are applied to meet the ones conditions, yet on the same time a a success controller is required for powerful manage. in this paper, an progressed programmed age manipulate $(A G C)$ with fluffy cause for a -zone heat hydro manage framework is exhibited. Contingent on the factors of burden, required suggestions are completed to improve enduring us of a and dynamic reaction of two-place manage framework. The adequacy of proposed controller is stated via making use of MATLAB/Simulink programming.

Watchwords - AGC, load recurrence control, MATLAB/SIMULINK.
\end{abstract}

\section{CREATION}

Presently a day's due to the fast development inside the populace, the strength request has likewise been growing. an excellent manner to meet this want, the interconnection of at least power systems is required.This interconnection need to resemble hydro-hydro, warm, aqueous, wind hydro, and so on. but, this interconnection may additionally spark off frequency fluctuations. So in order to say no the changes in recurrence and tie- line streams, load recurrence control (LFC) is wanted in power frameworks.

Writing check shows a part of the beyond works in LFC of an Inter associated framework [1],[2],[3],[4],. Execution of PI controller for interconnected power framework improves the relentless nation reaction however the dynamic response is un fundamentally affected [6]. because of this, in an effort to enhance the dynamic reaction, the improvement of a compelling fluffy reason controller (FLC) based AGC is needed.

\section{MATHEMATICAL MODELING}

2.1. Block Diagram instance of LFC of single region Thermal machine

A entire square graph portrayal of a solitary region warmth framework which includes senator, turbine, and power framework squares is seemed in the determine (1) Isolated Single Area Thermal System

Revised Manuscript Received on August 19, 2019.

V.Jahnavi Reddy, B.Tech Student, G.Narayanamma Institute of

Technology \& Science, Hyderabad, Telangana, India.

K.Krushna Murthy, Asst.Professor, G.Narayanamma Institute of

Dr.P.V.Bala Subramanyam, Professor, CMR College of

Engineering\& Technology . Hyderabad, Telangana, India.
Technology \& Science. Hyderabad, Telangana, India.

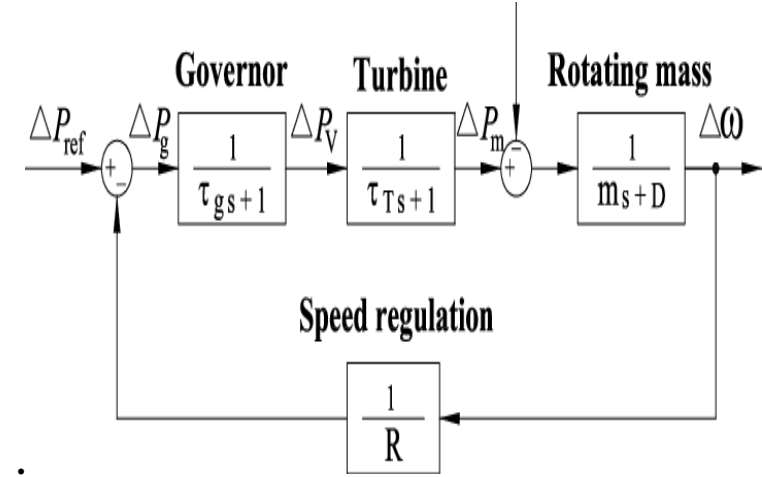

Fig.1: Block Diagram Model of LFC of an.

\subsection{Multi-Area Load Frequency Control}

A power framework can be partitioned into various control territories bury associated by methods for tie-lines. Give us a chance to consider a two-region warm hydro control framework which is interlinked by methods for a tieline.

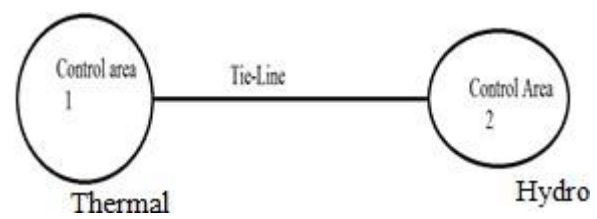

Fig.2: Thermal-Hydro Control areas interconnected with Single Tie-Line

For any exchange in load takes region in each the regions, the frequency of every place and additionally the strength in tie-line should be controlled. The change inside the frequency in a two region energy gadget is given by using equation (1)

$$
\Delta \mathrm{F}(\mathrm{S})=[\Delta \mathrm{PG} 1(\mathrm{~s})-\Delta \mathrm{PG} 2(\mathrm{~s})-\Delta \mathrm{PTie}, 1(\mathrm{~s})]^{*} \underline{\mathrm{Kps}} 1+\mathrm{Tps} 1 \mathrm{~s}
$$

The tie line power flow change in area- 1 is given by equation (2)

$$
\Delta \mathrm{PTie}, 1(\mathrm{~s})=\underline{2 \Pi \mathrm{T} 12}[\Delta \mathrm{F} 1(\mathrm{~s})-\Delta \mathrm{F} 2(\mathrm{~S})]
$$

Similarly, the tie line power flow change in area- 2 is given by equation (3)

$$
\Delta \text { PTie }, 2(\mathrm{~s})=2 \text { Ia } 12 \mathrm{~T} 12[\Delta \mathrm{F} 2(\mathrm{~s})-\Delta \mathrm{F} 1(\mathrm{~S})]
$$

The manipulate goal any load frequency controller is to modify frequency of every area in addition to to alter the tieline flows, so that the steady kingdom and dynamic response of power device is advanced.

Published By:

Blue Eyes Intelligence Engineering 


\section{IMPROVED AUTOMATIC GENERATION CONTROL OF INTERCONNECTED POWER SYSTEM}

\section{MANIPULATE STRATEGIES}

\subsection{Proportional + fundamental Controller:}

Proportional +critical (PI) controller is one of the pleasant traditional controller for any systems. Proportional +imperative controller is used for AGC to lessen the regular us of a frequency mistakes to zero [4]. but the fundamental downside of PI controller is that settling time is greater and the height overshoot is also immoderate. additionally the tuning of PI controller is a hard manner. The switch function model the PI controller is verified underneath,

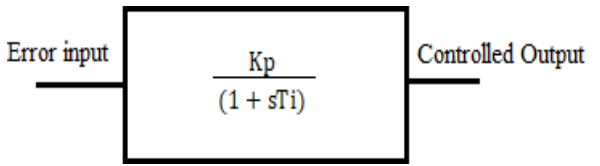

Fig.3: PI controller Model

\subsection{Fuzzy Logic Controller:}

Fluffy cause controller (FLC) is an non-obligatory strategy to dispense with the drawbacks of everyday PI controller applied for programmed age manipulate of a area framework [4]. The principle constructing squares of this controller are given under:

- Fuzzification

- Fuzzy Reasoning

- Fuzzy records base

- Defuzzification

This control technique has a extraordinary aspect that it may explicit etymologically complex direct frameworks. within the fuzzification technique the fresh set is changed over into a fluffy set. In mild of the fluffy features an enrollment capacity is selected that is maximum suitable to the application. At that point the fluffy preferred base is constructed up. From that factor onward, defuzzified fluffy set by way of making use of focus of gravity approach is created.

\subsection{Proposed Fuzzy common sense Rule Base:}

Within the proposed fluffy cause controller '9' regulations have been set up and are regarded in table 1. those recommendations are in "if and then position [6]. The recurrence blunder and alternate in recurrence mistake are considered as contributions to the controller.

\begin{tabular}{|c|l|l|l|}
\hline $\begin{array}{l}\text { Error/Change } \\
\text { in Error }\end{array}$ & NB & ZE & PB \\
\hline NB & NB & NB & ZE \\
\hline ZE & NB & ZE & PB \\
\hline PB & ZE & PB & PB \\
\hline & & & \\
\hline
\end{tabular}

Table 1: Fuzzy Rule Base

Gaussian membership function is used in the proposed controller which is shown in Fig.4 and Fig.5.

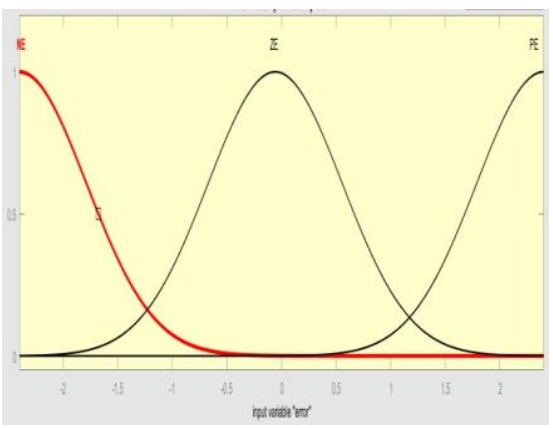

Fig.4: Membership Function for Error Input.

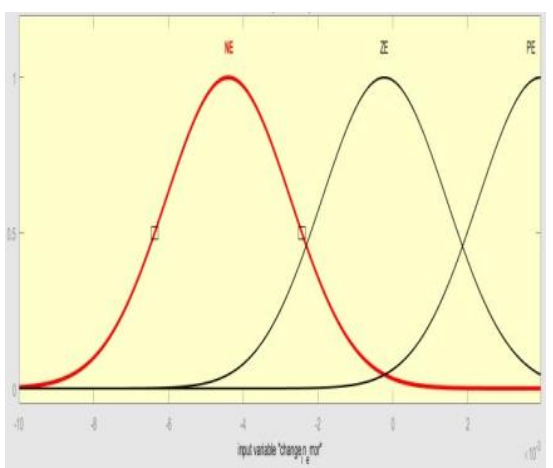

Fig.5: Membership Function for Change in Error Input.

\subsection{MATLAB Simulink Models:}

Two area thermal hydro model without using any controller is shown in Fig.6:

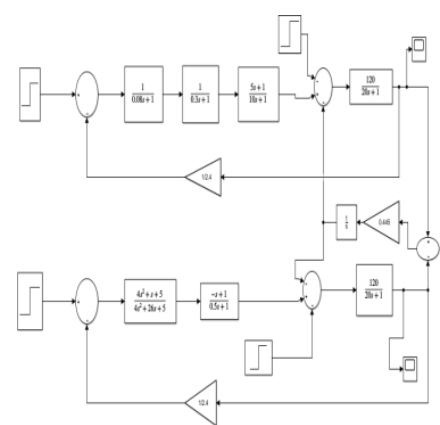

Fig.6: Uncontrolled Model of Thermal- Hydro System.

Two area thermal hydro system with PI controller is shown in Fig.7:

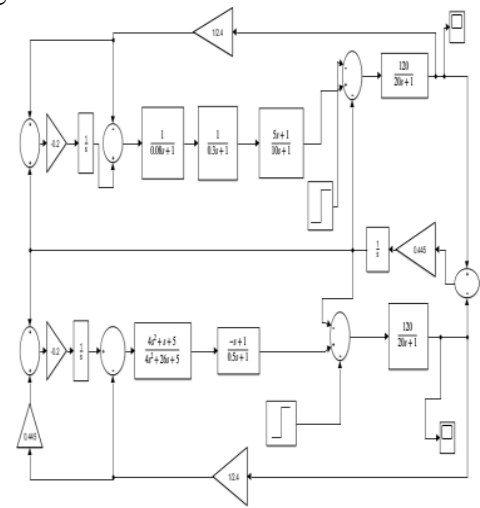

Fig.7: PI Control Model of Thermal-Hydro System.

Two area thermal hydro system with Fuzzy logic controller is shown in Fig.7:

Published By: 


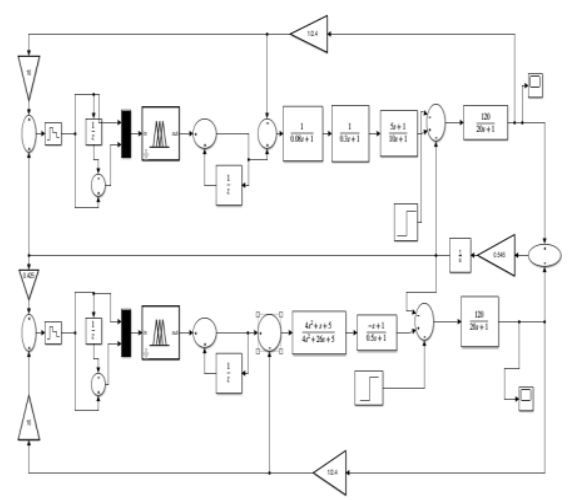

Fig.8: Fuzzy Logic Control Model of Thermal-Hydro System.

\section{RESULTS \& COMPARISONS}

Simulation turned into achieved on two areas thermalhydro gadget the use of PI and Fuzzy logic Controllers and the consequences have been as compared.

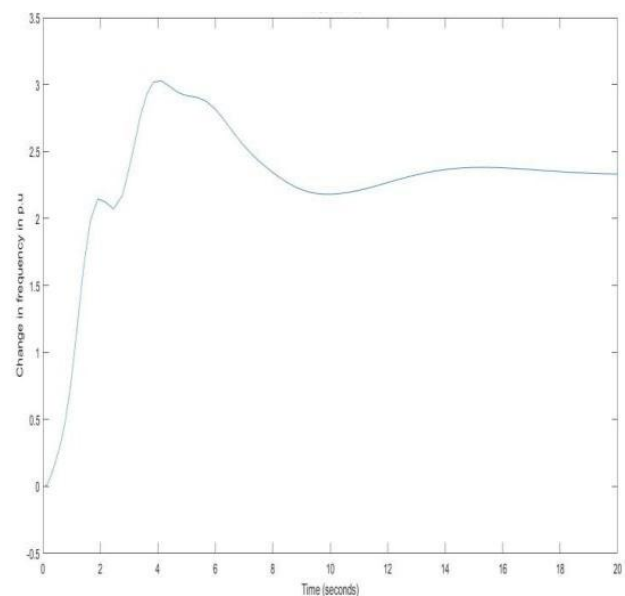

Fig.9: Frequency Deviation Step Response of Uncontrolled Thermal System.

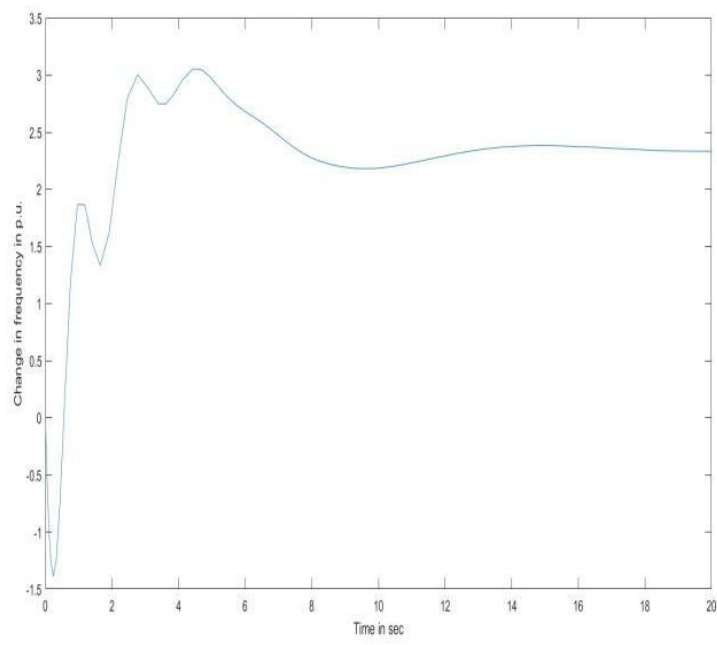

Fig.10: Frequency Deviation Step Response of Uncontrolled Hydro System.

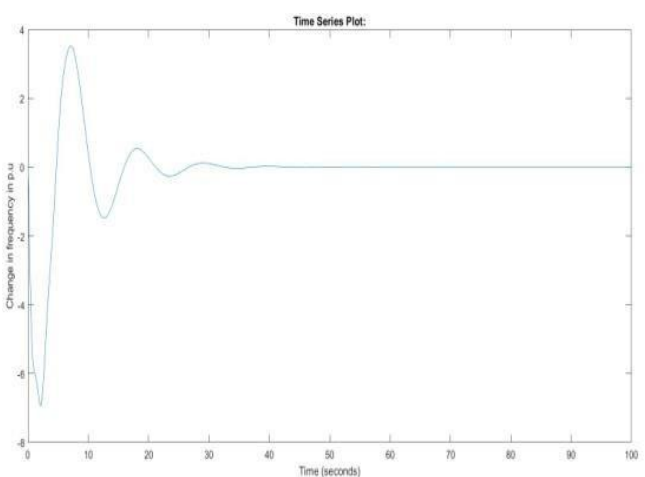

Fig.11: Frequency Deviation Step Response of PI controlled Thermal System.

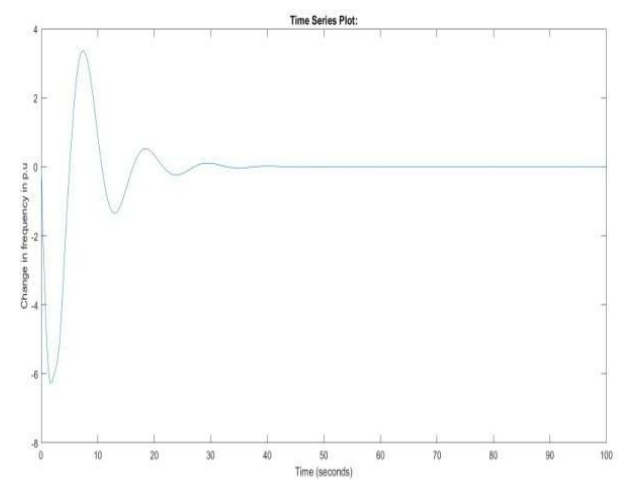

Fig.12: Frequency Deviation Step Response of PI controlled Hydro System.

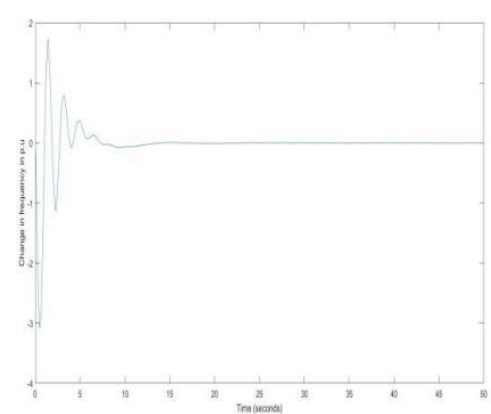

Fig.13: Frequency Deviation Step Response of Fuzzy Controlled Thermal System.

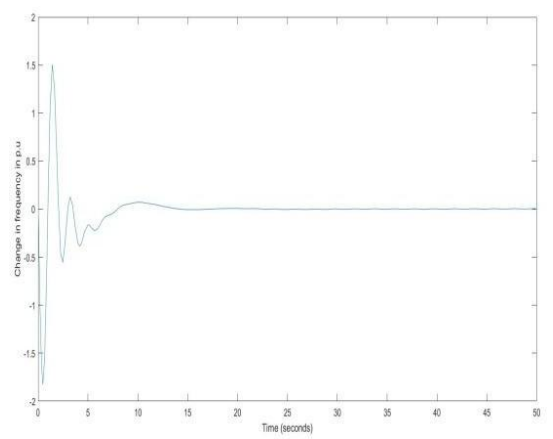

Fig.14: Frequency Deviation Step Response of Fuzzy Controlled Hydro System.

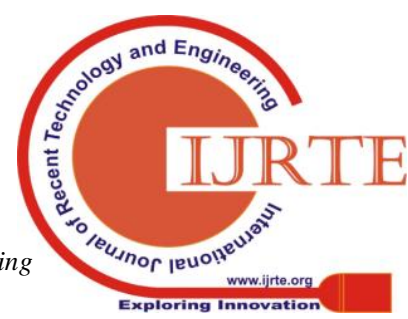




\begin{tabular}{|c|c|c|c|}
\hline Parameter & $\begin{array}{c}\text { Steady } \\
\text { state } \\
\text { error } \\
\text { (p.u) }\end{array}$ & $\begin{array}{c}\text { Settling } \\
\text { time }\left(\mathbf{T}_{\mathbf{S}}\right) \\
\text { in sec }\end{array}$ & $\begin{array}{c}\text { Peak } \\
\text { Over } \\
\text { shoot } \\
\text { (p.u) }\end{array}$ \\
\hline $\begin{array}{c}\text { Without } \\
\text { Controller }\end{array}$ & 2.4 & 17 & 3 \\
\hline $\begin{array}{c}\text { With PI } \\
\text { controller }\end{array}$ & 0 & 35 & 3.85 \\
\hline With FLC & 0 & 14 & 1.73 \\
\hline
\end{tabular}

Table 2: Comparison of Two Area Termal- Hydro System Using PI and FLC.

\section{CONLUSION}

A hit programmed age manipulate of an interconnected power framework is essential for alleviating the dynamic adjustments in recurrence simply as tie line power streams. From the effects acquired in the beyond areas, it thoroughly may be presumed that the proposed controller offers advanced effective reaction than everyday PI controller. The proposed controller offers 0 unfaltering kingdom blunder and diminishes the settling time just as pinnacle overshoot to a widespread degree.

\section{REFERENCES}

1. G. Concordia C., and Krichmayer L.ok., (1954), "Tie-line have an effect on and recurrence manage of have an effect on frameworks phase 2", AIEE Transactions,133-146,April.

2. Kundur P. 1994. "electricity system stability and manage". Mc-Graw Hill, ny .

3. Abdennour A., (2002), "flexible most appropriate gain Scheduling for the weight Frequency manage problem", electric powered powered strength additives and systems, vol. 30(1), 45-56.

4. Surya Prakash, Sunil Kumar Sinha, Ajay shekar Pandey. 2008 "effect of slider advantage on burden recurrence manage the use of fluffy cause controller". global meeting of studying.

5. ShashiKant Pandey, Soumya R. Mohanty, NandKishor, "A writing have a have a look at on burden recurrence manage for ordinary and appropriation age manipulate frameworks," ELSEVIER Renewable and Sustainable strength reviews, vol.25, pp.318-334, 2013.

6. Krishna Chaitanya Digevi, Ravali Pinnapureddy. 2017. "exam of Load Frequency control for Multi vicinity tool PI and Fuzzy common sense Controllers". choose out. Eng. Trans., 3239-6/17.

\section{APPENDIX}

Heat gadget: Time everyday of Governor $\mathrm{Tg}=0.08 \mathrm{sec}$ Time everyday of Turbine $\mathrm{Tt}=\mathrm{zero} .3 \mathrm{sec}$ Time steady of Re-radiator $\mathrm{Tr}=10 \mathrm{sec}$ advantage of Reheater $\mathrm{Kr}=0$.three velocity regulation Rth $=2.4 \mathrm{~Hz} / \mathrm{pu}$ MW Hydro gadget: rest Time of Governor TR=five.0sec Time everyday of droop $\mathrm{TRH}=28.75 \mathrm{sec}$ Time consistent of important Servo $\mathrm{TGH}=\mathrm{zero} .2 \mathrm{sec}$ Time steady of Water $\mathrm{TW}=1.0 \mathrm{sec}$ pace law Rhy $=2.4 \mathrm{~Hz} / \mathrm{pu} \mathrm{MW}$

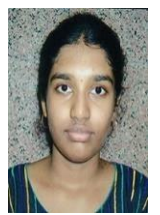

V. Jahnavi Reddy is completed her B.Tech. from G.Narayanamma Institute of Technology \& Science for Women affiliated to JNTUH. Her areas of research include Power Systems, Control Systems.

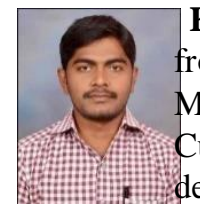

K.Krushna Murthy is received his B.Tech. from Vagdevi College of Engineering, and M.Tech from JNTUH College of Engineering. Currently, he is associated with EEE department of G.Narayanamma Institute of Technology \& Science for Women affiliated to JNTUH as an Asst.Professor. His areas of research include Advanced Power Systems Operation and Control, Modern Power System Analysis.

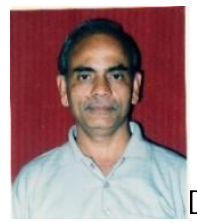

Dr.P.V. Bala Subramanyam is received his Ph.D. from Banglore University in 1997. He has a rich experience with R\&D centre of CPRI, Hyderbad. He worked as professor at CBIT. Currently, he is associated with EEE department, CMRCET as profressor. His areas of research includes modern power systems and application of power electronics to power systems. 